\title{
Genomic medicine in Mexico: Initial steps and the road ahead
}

\author{
Gerardo Jimenez-Sanchez, ${ }^{1}$ Irma Silva-Zolezzi, Alfredo Hidalgo, and Santiago March
}

National Institute of Genomic Medicine, Mexico D.F. 01900, Mexico

\begin{abstract}
Mexico faces important demographic and epidemiological transitions with significant implications to patterns of disease, disability, and death. On the one hand, there are problems of underdevelopment and, on the other, the emerging challenges of the chronic and degenerative diseases of the industrialized world. For these diseases, prevention becomes a key strategy for alleviating a major burden to the economy and health of the Mexican population. Genomic medicine has become a priority to the Mexican government as a means of finding new strategies to tackle common diseases. In 2000, strategic planning for genomic medicine began, from a feasibility study and a multi-institutional consortium effort, to the creation of a National Institute of Genomic Medicine by the Mexican congress in 2004. Current research programs in genomic medicine in Mexico include the construction of a haplotype map of the Mexican population, several genome-wide association studies for common diseases, such as diabetes, obesity, cardiovascular disease, and cancer, as well as translational medicine projects that include biomarkers discovery for several kinds of cancer, pharmacogenomics, and nutrigenomics. Although this strategy has been successful, there are challenges that still need to be addressed, including increased investment in science and technology to stimulate a more vigorous and competitive research environment, development of more effective basic and clinical research synergies, recruitment and training of more human resources in genomic medicine, developing mechanisms to stimulate translational research, and developing a more modern regulatory framework to ensure that genomic medicine will successfully contribute to improve healthcare in the Mexican population.
\end{abstract}

As the results from the Human Genome Project became available, many opportunities emerged for science, technology, medicine, economy, and society. In addition to the complete sequence of the human genome (International Human Genome Sequencing Consortium 2004), a map containing close to 23,000 genes, and a catalog of over 1200 disease genes (Jimenez-Sanchez et al. 2001), genomic variations that contribute to genetic individuality, have been systematically identified. These include single nucleotide polymorphisms (SNPs), copy number variations $(\mathrm{CNV})$, and segmental duplications or deletions, among others (Wakeley et al. 2001; Iafrate et al. 2004; Sebat et al. 2004). Furthermore, the HapMap Project (The International HapMap Consortium 2005) has provided a set of fundamental tools that contribute to the identification of the genomic basis of common diseases. Moreover, the "1000 Genomes" (Kaiser 2008) and the creation of new sequencing technologies promise to increase our knowledge and accelerate the development of genomic sciences and its medical applications.

Genomic medicine, understood as the systematic use of genomic variation to identify risks for common diseases, will lead a more individualized, more predictive, and more preventive medical practice based on the genetic risk factors of an individual. In turn, this will lead to more effective interventions specific for the individual. Genome-wide association studies (GWAS) have shown important steps toward identifying genetic risks for common diseases, leading, in recent months, to the identification of genetic markers for several common diseases including diabetes (The Wellcome Trust Case Control Consortium 2007), heart disease (The Wellcome Trust Case Control Consortium 2007), Crohn's

\section{Corresponding author.}

E-mail gjimenez@inmegen.gob.mx; fax 52-55-5350-1950.

Article is online at http://www.genome.org/cgi/doi/10.1101/gr.065359.107.

Freely available online through the Genome Research Open Access option. disease (Mathew 2008), and several types of cancers (Easton et al. 2007; Zanke et al. 2007). The availability of this information opens not only the possibility of more accurate screening systems, diagnosis, and prognosis of common diseases, but also the potential for new treatment targets and drug development.

This new paradigm offers important opportunities for scientific research and public health by offering the potential to develop knowledge to prevent, or at least delay the onset of many common diseases. Such strategies would not only decrease chronic complications and related costs, but they would also improve healthcare, quality of life, and possibly lead to a more rational use of resources and better supported public health decisions. Herein, we reference several efforts launched in Mexico in the last decade and outline a strategy for a national platform of genomic medicine that will improve the healthcare of the Mexican population.

Historic and demographic background of the Mexican population

Mexico is the fourteenth largest country in world, with a total area of $1,972,550 \mathrm{~km}^{2}$ and more than 105 million inhabitants (INEGI 2005). Its vast size and varied topography lead to a wide variety of climatic conditions, from the arid deserts in the north to tropical rainy climates in the south and southeast coastal areas.

Geographically distant regions in Mexico have different population dynamics related to both the different ancestral components and the demographic conditions affecting each region (Gerhard 1996). During the prehispanic period, most of the population was concentrated in the central and southern part of Mexico. Ethnic groups inhabiting northern Mexico did not have linguistic, religious, or politic unity. Not until two centuries after the conquest did the northern regions attract the attention of the 
Spaniards, mainly as a consequence of silver deposits discovered there (Gerhard 1986). African slaves were brought into Mexico after the Amerindian population was notably reduced by epidemics between 1545 and 1548. Africans frequently intermixed with both indigenous and Mestizo individuals, but many others were taken to other regions for mining work. The Yucatan Peninsula, in southeast Mexico, was populated by different Amerindian groups that were decimated by diseases that reduced the original population by more than half (Gerhard 1991). This unique history resulted in a population that derives from more than 60 local Amerindian groups, Europeans, and, to a lesser extent, Africans. To this date, there is a census of Amerindian groups according to their language and geographical location (http://www.cdi.gob.mx/index.php?id_seccion=660). These groups have intermixed over the past $500 \mathrm{yr}$, leading to the "Mestizo" population that represents over $80 \%$ of Mexicans today (Gonzalez Burchard et al. 2005). This demographic history makes it important to characterize the genetic makeup of the Mexican population as an initial step for effectively developing genomic medicine in Mexico.

\section{Constructing the way into genomics}

In the past decade, Mexico's Government has been strengthening its commitment to improve competitiveness and innovation through science and technology. Although investment in this area has been consistently limited in Mexico, from 1995 to 2005 the percentage of the Gross Domestic Product (GDP) allocated to science and technology has increased from 0.35 to 0.43 . The number of students enrolled in science and technology Ph.D. programs has increased from 488 in 1994 to 2009 in 2005, and from 2001 to 2005 , the number of researchers under the National Science and Technology System has increased by $62 \%$ (Triunfol 2007). Moreover, in 2002, the Mexican Congress passed a new Science and Technology Law, creating new funds for science and technology called Sectorial Funds. These funds are composed by equal contributions from ministries, states, and districts, and the National Council for Science and Technology (CONACYT).

Today, Mexico has over 12,100 investigators registered by the National System of Investigators. Of these, $24.5 \%$ are at the National Autonomous University of Mexico (UNAM), followed by public State Universities across Mexico. In medical research, the National Institutes of Health account for $\sim 500$ (3.9\%) investigators, the Mexican Institute of Social Security (IMSS) accounts for 294 (2.4\%), and other areas of the health sector account for 87 $(0.7 \%)$. Biology and Chemistry and Medicine and Health Sciences account for $26.7 \%$ of the total number of investigators, showing a sustained increase over the last $10 \mathrm{yr}$ (CONACYT, www.siicyt. gob.mx). Although the number of investigators is still limited, the trends show a clear increase in numbers as well as the academic level of training.

In the past $15 \mathrm{yr}$, important ground-breaking efforts in genomic sciences have taken place in Mexico. This includes participating in the Escherichia coli genome project (Blattner et al. 1997) as well as the first large-scale sequencing project in Mexico, namely, the Rhizobioum etli genome, developed at the Center for Genomic Sciences (CGS) (www.ccg.unam.mx) at the UNAM, formerly the Center for Nitrogen Fixation (CIFN) (Gonzalez et al. 2006). These and other projects led to a series of genomics initiatives related to different organisms, including the human parasite Taenia solium, the genome of which is also currently being sequenced at UNAM (Aguilar-Diaz et al. 2006). Other genomic projects include plant species, where the major effort is at the Center for Research and Advanced Studies (CINVESTAV) (www.cinvestav.mx). The National Laboratory of Genomics for Biodiversity (LANGEBIO) was recently established to conduct important genomics programs in plants, such as the sequencing and functional analysis of the maize genome. Additional infrastructure for genomics research is located in the states of Guanajuato, Nuevo Leon, Jalisco, Tamaulipas, and Yucatan, among others (Fig. 1).

In 2004, a new Undergraduate Program in Genomic Sciences (LCG) was launched at UNAM (www.lcg.unam.mx) and hosted by the CGS and Institute of Biotechnology in Cuernavaca, State of Morelos. The curriculum includes intensive training in mathematics, statistics, computer sciences, and biology, and it aims to produce new generations of professionals who will contribute to the genomic sciences in Mexico (Palacios and ColladoVides 2007). In recent years, two new scientific societies were founded: the Mexican Society of Genomic Sciences (http:// smcg.ccg.unam.mx/) and the Mexican Society of Genomic Medicine (www.somegen.org.mx). These societies bring together most of the scientists working on genomics in Mexico.

\section{From human genetics to genomic medicine}

Mexico has a long tradition in the biomedical and health sciences. In the 1950's, the study of human and biochemical genetics began with the description of blood group distribution in Mexican populations. Today, over 250 professionals are registered in the Mexican Association of Human Genetics, there are more than 175 certified geneticists registered by the Mexican Council in Genetics, and a variety of institutions offer over 50 independent formal graduate courses in human genetics and molecular biology. As a result, independent human genetics research groups have been established in areas including clinical genetics, cytogenetics, genetic epidemiology, population genetics, inborn errors of metabolism, neonatal screening, genetic toxicology, and molecular genetics (Salamanca and Armendares 1995).

Historically, most major contributions to genetic research on Mexican-Americans have been produced outside of Mexico, with some produced in collaboration with Mexican researchers. In Mexico, most of the studies of the genetic basis of common complex diseases have primarily analyzed known associated variants in candidate genes. Initially, those studies included the association of the HLA-B27 allele to Ankylosing Spondylitis (Fraga et al. 1979) as well as the association of other HLA alleles with rheumatoid arthritis (Arellano et al. 1984). Since then, associations between HLA alleles and several common complex diseases, including type II diabetes and its complications (Perez-Luque et al. 2003), systemic lupus erythematosus (SLE) (Bekker-Mendez et al. 1998), Scleroderma (Vargas-Alarcon et al. 1995), type I diabetes (Gorodezky et al. 1995), and others, have been described in Mexicans. Several other complex diseases have been studied using candidate gene approaches.

Examples include the analysis of SNPs associated with different abnormalities in serum lipid levels in genes encoding insulin (INS) (Sanchez-Corona et al. 2004), hepatic nuclear factor 4-alpha (HNF4A) (Weissglas-Volkov et al. 2006), tumor necrosisalpha (TNF) (Parra-Rojas et al. 2006), and ABCA1 (VillarrealMolina et al. 2007). In addition, associations to SLE have been described for polymorphisms in PTPN22 (Baca et al. 2006) and PDCD1 (Velazquez-Cruz et al. 2007) in pediatric patients and for the latter in adult patients (Prokunina et al. 2002).

The $677 \mathrm{C}>\mathrm{T}$ polymorphism in the methylene tetrahydrofo-

\section{Genome Research}

www.genome.org 


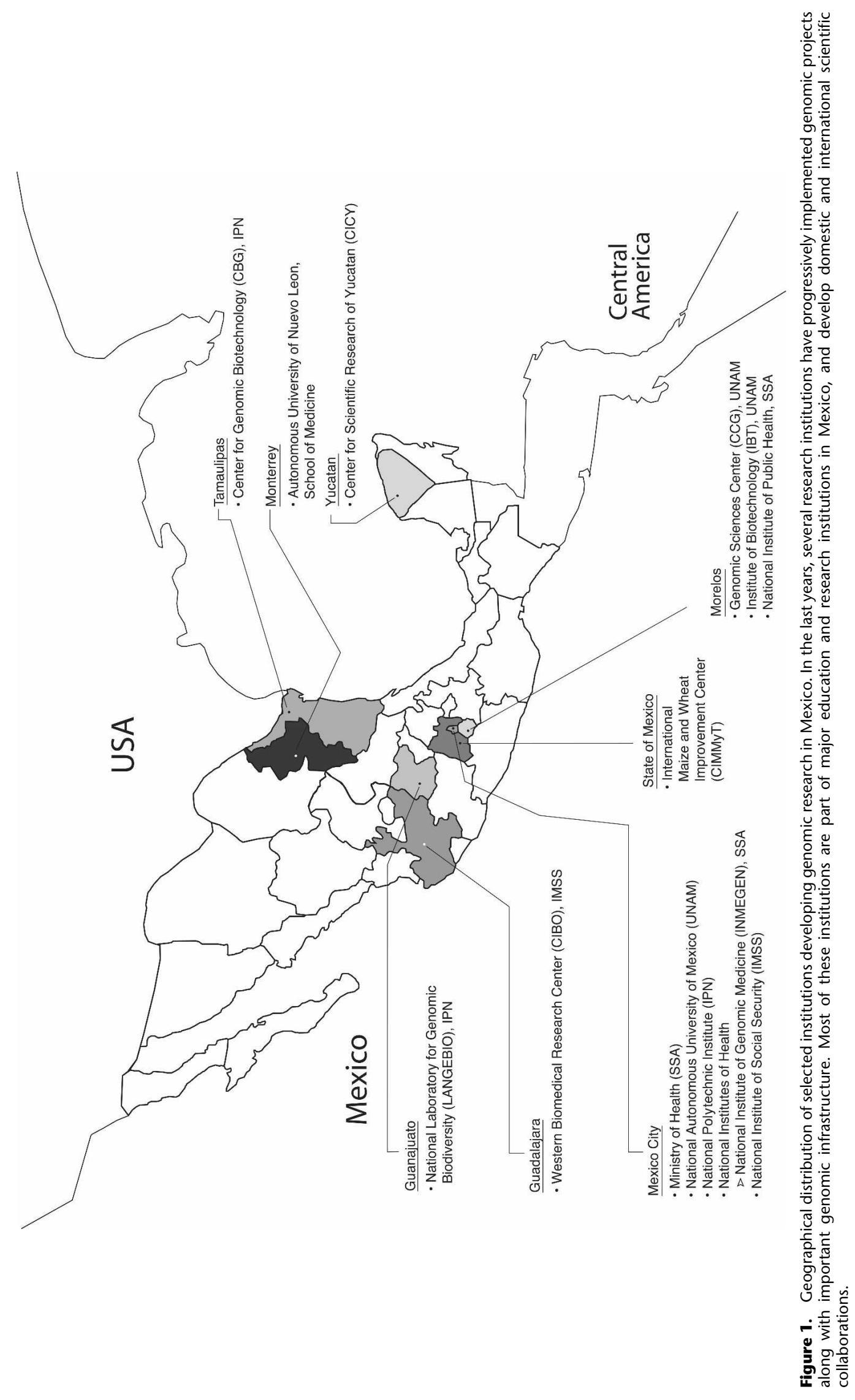


late reductase gene (MTHFR) is associated with diseases related to hyperhomocystinemia and folate deficiency. In Mexicans, the $677 \mathrm{C}>\mathrm{T}$ allele has been found to be mildly associated $(P=0.05$ 0.01) with hyperhomocysteinemia (Torres-Sanchez et al. 2006), anencephaly (Munoz et al. 2007), and gastric cancer (LacasanaNavarro et al. 2006). As an example of the effects of admixing in Mexico, the Mexican Mestizo population shows the highest prevalence reported of both the risk allele $(\mathrm{T})$ and the homozygous genotype (TT) (Wilcken et al. 2003; Gueant-Rodriguez et al. 2006), most likely as a result of some of the highest frequencies of the T allele shown in Mexican Amerindian groups (Davalos et al. 2000).

Analyses of genetic variations related to drug responses have been mainly focused on genes encoding metabolizing enzymes, such as CYP2D6. For this gene, allelic frequencies show significant differences in different populations across Mexico. For example, $C Y P 2 D 6^{*} 10$ has a frequency of $12.45 \%$ in individuals from Mexico City (Lopez et al. 2005), but only 2.3\% in those from Durango, a northern state of Mexico (Sosa-Macias et al. 2006). Limited success in finding genetic associations with common metabolic diseases in Mexicans underlines the need for more robust experimental designs. These include GWAS, dense genotyping, and resequencing of candidate regions and genes derived from genome-wide scans to effectively identify genetic risk variants in complex diseases.

Genomic analysis of cancer in Mexico is experiencing a transition from the classical genetic approaches to the generation and management of genome-wide analysis using highthroughput genomic technologies. Genomic methods, including genome-wide expression and DNA copy number variation analysis (Hidalgo et al. 2005; Valladares et al. 2006; Vazquez-Ortiz et al. 2007), as well as serial analysis of gene expression (PerezPlasencia et al. 2005), have powered the study of cervical and breast cancers, and the application of genomic analysis of other cancers is becoming more common.

To develop human genetics and genomic medicine in Mexico, the country will require more robust study designs based on the known genetic structure of the Mexican population and the collection of large number of samples in different diseases. It will further require more health professionals to be trained in the field and the generation of public awareness to address the benefits and challenges of genomic medicine.

\section{The groundwork for genomic medicine in Mexico}

Like most developing countries, Mexico faces demographic and epidemiological transitions with important implications to the patterns of disease, disability, and death. Mexico faces, on one hand, the unsolved problems of infections, malnutrition, and reproductive health problems and, on the other hand, the emerging challenges of the chronic and degenerative diseases of the industrialized world. The adult population in Mexico has a high prevalence of diabetes (7.0\%), hypertension (30.8\%), and obesity (29.4\%) (Olaiz-Fernandez et al. 2006), and the two most frequent causes of death are cardiovascular diseases (22.9\%) and diabetes (15.3\%) (INEGI 2006). For these health problems, prevention becomes a key strategy to alleviate a major burden to the economy and health of the Mexican population.

In 2000, an initial work group analyzed the opportunities that genomic medicine could represent for Mexico. They identified eight areas of opportunity: (1) contribution to a more individualized, more predictive, and more preventive medical practice; (2) strengthening scientific research and technology in
Mexico; (3) potential for cost reduction in healthcare; (4) development of pharmacogenomics; (5) generation of new goods and services; (6) strengthening potential to participate in knowledge economy; (7) timely development of an ethical and legal framework for genomic medicine in Mexico; and (8) public educational programs related to genomics and society among others. To identify such important opportunities for Mexico, a strategic alliance was established by four key institutions: the Ministry of Health (SSA), UNAM, CONACYT, and the Mexican Health Foundation (FUNSALUD). This alliance conducted and financed a feasibility study between 2001 and 2002 with the collaboration of over 65 participants from different institutions across the country. The study evaluated scientific, technological, academic, operative, organizational, economic, social, and political feasibility. It also produced a detailed analysis of the cost of not developing genomic medicine in Mexico. This part of the study identified high social, health, scientific, technological, economic, and ethical costs for Mexico if genomic medicine were not developed in a timely manner. In addition, it laid out a detailed plan to implement a strategy that would include a National Institute of Genomic Medicine within the Mexican NIH that would coordinate efforts across the country and develop a national platform for genomic medicine in Mexico (Jimenez-Sanchez 2002a,b, Jimenez-Sanchez et al. 2003).

A bill to create a new NIH was presented to the Mexican Congress in 2002. The four-institution alliance created a Consortium for the Institute of Genomic Medicine that would carry out strategic planning and preparatory work, including fundraising, establishing initial infrastructure, and identifying human resources both in Mexico and abroad. In addition, this Consortium would help set up outreach programs and initial graduate courses in genomic medicine and other important activities that were essential for the creation of the National Institute of Genomic Medicine in July 2004.

\section{The National Institute of Genomic Medicine (INMEGEN)}

INMEGEN (www.inmegen.gob.mx) is one of 12 NIHs of Mexico and has the mission of contributing to the healthcare of Mexicans by developing world-class scientific research and highquality human resources, leading to medical applications of genomic knowledge through an innovative culture, state-of-the-art technology, and strategic alliances, and also observing universal ethical principles. INMEGEN is a cornerstone of the Mexican strategy to develop a national platform in genomic medicine. It is designed to grow as an autonomous institution with strong links to the education and health sectors across the country. INMEGEN's 2004-2009 Work Program (Jimenez-Sanchez 2004) includes nine strategies (Table 1) with specific milestones. Its main source of funding consists of federal fiscal funds, although it also receives funds from domestic and international grants, as well as donations from private institutions. During its first $3 \mathrm{yr}$ of operation, the Mexican government has allocated over \$125 million USD for initial operations and infrastructure. It includes state-of-the-art facilities in Mexico City, including highthroughput core centers for sequencing, genotyping, expression, high-performance computing, biomarker discovery, and validation. In addition, INMEGEN has established a Research Center in Ethical, Legal, and Social implications of genomic medicine and a Business Incubator and Technology Transfer facility. INMEGEN will soon open a new $60,000-\mathrm{m}^{2}$ facility in the NIH campus in Mexico City.

\section{Genome Research}

www.genome.org 
Table 1. Nine strategies to develop the National Institute of Genomic Medicine

1. Build an innovative organizational design: The INMEGEN system.

2. Establish the initial infrastructure.

3. Make strategic alliances for the Nationwide Development of Genomic Medicine.

4. Perform high-quality scientific research in genomic medicine.

5. Apply world-class genomic technology to common health problems.

6. Reach excellence in teaching and training programs.

7. Support scientific research and academic programs.

8. Comply and investigate on ethical, social, and legal issues.

9. Translate scientific knowledge into products and services.

These strategies and specific actions were the basis of INMEGEN's 20042009 Work Program. During the first $3 \mathrm{yr}$, the Institute has been successful in implementing more than $85 \%$ of these strategies.

The scientific agenda of INMEGEN is oriented toward understanding the genomic structure of the Mexican population and studying its most common health problems, including diabetes, obesity, cardiovascular diseases, infections, autoimmune diseases, and age-related macular degeneration along with thyroid, breast, prostate, and blood neoplasias. Most projects are related to identifying common disease genes and biomarkers for diagnosis and prognosis (Table 2 ). In addition, pharmacogenomics is an important part of the scientific agenda, since it stands to generate strategies for more effective and less toxic medications for the Mexican population (Seguim et al. 2007).

An essential tool to develop genomic medicine in Mexico is a haplotype map of the Mexican population, given that the HapMap did not include any population from Latin America (The International HapMap Consortium 2005). Mexican Mestizos are a recently admixed population mostly composed of European, Amerindian, and African ancestries. Genetic heterogeneity in Mexicans results from a range of different population dynamics in geographically distant regions. We developed the Mexican Genome Diversity Project and genotyped 110,356 SNPs for phase I from 300 nonrelated self-identified Mestizo individuals from six geographically distant regions in Mexico. We then evaluated the genetic diversity, LD patterns, and extent of haplotype sharing using genome-wide data from these individuals together with data from the HapMap (A. Hidalgo-Miranda, J.K. Estrada-Gil, I. Silva-Zolezzi, L. Uribe-Figueroa, A. Contreras, L. del Bosque-Plata, C. Lara Alvarez, R. Goya, J.C. Fernandez-Lopez, E. HernandezLemus, et al., in prep.). Our results indicate that although there are some regional genetic differences between Mexican subpopulations, they are similar enough to be analyzed as a single group. Nevertheless, results from this study provide evidence of a population structure among Mexicans that must be considered when designing and analyzing genomic and genetic association studies. Initial analysis, using a set of 2824 ancestry informative markers derived from the three HapMap populations, indicated different proportions of admixture in Mestizos, and made evident a fourth ancestral component in various proportions corresponding to the Amerindian contribution (J.K. Estrada-Gil, I. Silva-Zolezzi, A. Hidalgo-Miranda, J.C. Fernandez-Lopez, E. Hernandez-Lemus, R. Goya-Ogarrio, I. Peer, and G. Jimenez-Sanchez, in prep.). Results from this project indicate that a haplotype map from Mexican Mestizos would improve the selection of tagSNPs to cover common genetic variation in association studies for common diseases in the Mexican population. This is the first genome-wide genotyping effort of a recently admixed Latin
American population available in the public domain (http:// diversity.inmegen.gob.mx).

To comprehensively cover common genetic variation and adequately describe the genomic structure of Mexicans, we are increasing the SNP density to $\sim 1.5$ million, and we will include Amerindian populations in this analysis. Results derived from these efforts will provide the basis for translating knowledge of the genetic structure of our population into a better understanding of common complex diseases. Additional studies of genomic structure include the systematic analysis of CNV studies in Mestizo and Amerindian populations. Moreover, INMEGEN is conducting GWAS studies for age-related macular degeneration, diabetes, obesity, lupus, and cardiovascular diseases, as well as expression analysis in lung, thyroid, and prostate cancer, and leukemias and sarcomas in both humans and in mouse models. In the area of medical proteomics, INMEGEN is developing biomarker discovery projects in melanoma, lung, and breast cancer by analyzing proteomic profiles in blood, saliva, and human tissues.

Along with scientific research in genomic medicine, different educational training efforts have been initiated. In 2003, three graduate courses in genomic medicine were launched as part of the Doctoral Program in Medical Sciences of UNAM. Today, INMEGEN offers these and undergraduate courses in different areas of genomic medicine, and it will soon open two new courses in bioinformatics and oncogenomics. In addition, the National Association of Medical Schools (AMFEM) of Mexico is proposing the incorporation of genomic medicine into the medical school curriculum. Other instruments to convey information to professionals and nonprofessionals include two National Congresses of Genomic Medicine (2004 and 2006) and several publications, including a comic series for children ages 10-12. In addition, INMEGEN's web portals in Spanish and English are widely consulted. In 2007, over 11 million hits were registered, and more than 9 million

Table 2. Selected research projects at INMEGEN

\begin{tabular}{ll}
\multicolumn{1}{c}{ Projects } & Field \\
\hline 1. Construction of a 1,500,000 SNPs & Population genetics \\
Haplotype Map of the Mexican & \\
population. & Population genetics \\
2. Genomic structure of Mestizo and & \\
Amerindian populations. & Population genetics \\
3. DNA copy number variation in Mestizo & \\
and Amerindian populations. & Genome-wide and \\
4. Identification of genetic variation & candidate gene \\
associated with common complex & association studies. \\
diseases: & \\
- Diabetes Mellitus & \\
- Cardiovascular diseases & \\
- Obesity & \\
- Autoimmune diseases (SLE, RA, others) & \\
- Asthma & \\
- Age-related macular degeneration & Translational medicine \\
5. Cancer Genomics and Proteomics: & \\
- Breast & \\
- Gung & \\
- Pastric & \\
- Thyratate & \\
- Melanoma & \\
6. Pharmacogenomics & Translational medicine \\
7. Nutrigenomics & Translational medicine \\
\hline
\end{tabular}

These priorities were mainly selected according to the prevalence of diseases among the Mexican population. 
documents were downloaded from 41 countries. INMEGEN has developed several strategic alliances with 12 state universities, UNAM, the Mexican NIH, and ISSSTE, in Mexico, as well as the Translational Genomics Research Institute (TGen), Vanderbilt University, the New York State Center of Excellence in Bioinformatics and Life Sciences, the University of Toronto, and Nestlé, abroad.

\section{Current challenges}

Developing genomic medicine in Mexico and taking it to a leadership level where medical applications will actually improve healthcare for the Mexican population require more than good science. This ambitious goal requires some cultural changes, including a serious team effort from clinicians and basic scientists, and it also requires a focus on common goals to tackle national health problems such as diabetes or breast cancer as opposed to individual, unrelated, or duplicated projects. In addition, it is important that the Mexican model encourages a serious component of innovation and translational research in genomic medicine. In general, these challenges are better incorporated by the younger generations.

There are, however, other challenges, including the need for novel funding mechanisms and incentives to innovate and register intellectual property outside of the traditional format that conditions a significant proportion of scientists' income, creating a legitimate urge to publish results. While this system has been proven to increase the number and quality of scientific publications, it does not stimulate innovation where the risk of failure is significantly higher, and publication usually comes after registration of intellectual property. In recent years, the Mexican government has implemented programs to stimulate innovation and generate new business models based on scientific knowledge. These programs, based in CONACYT, reflect an awareness in the federal government of the strategic importance of innovation for economic growth (Foro Consultivo Cientifico y Tecnológico 2006). INMEGEN has established a synergy with CONACYT and the Mexican Institute of Industrial Property (www.impi.gob.mx) to develop mechanisms to incorporate innovation into the local genomic medicine community. Although there are several genomic projects that are solely developed by Mexican scientists, many of them are usually produced under international collaborations, where Mexican scientists tend to ship samples to countries with a more robust infrastructure to join forces and accelerate their research. While international collaborations are desirable and encouraged, as Mexican groups increase scientific and technological critical mass, collaborations are shifting to a more equal contribution level, and more independent research is carried out.

Although several training programs in genomic medicine have been recently implemented, the number of applicants has significantly raised from tens to hundreds only at INMEGEN and LCG. This clearly indicates the need for new training programs in genomic sciences to satisfy the needs of the current generations. In addition, there is still a need for young investigators to actively develop genomic medicine in Mexico. Unfortunately, "brain drain" remains a major problem, mainly due to the lack of competitive salaries, appropriate infrastructure, and research funding opportunities across the country. The challenge for genomic medicine includes recruiting and bringing back well-trained professionals and finding a way to maintain them long enough to successfully develop scientific contributions. In recent years, this is being enhanced by better infrastructure and robust research programs that attract young investigators back to Mexico. CONACYT is overcoming this challenge by implementing a repatriation program and another program aimed at keeping young scientists in Mexico. As a result, 845 scientists returned to Mexico between 2001 and 2005, including some for our genomic medicine program.

Funding limitation is a global challenge for science. Mexico's investment in research and development (R\&D) is the lowest of the Organisation for Economic Co-operation and Development (OECD) country members, approximately one-seventh of the OECD average, and it is significantly lower than other emerging economies, such as China $(0.7 \%)$, India $(0.8 \%)$, or Brazil (at least $0.8 \%$ ) (OECD 2008). Compared with other countries in Latin America, in 2004 Mexico invested $0.41 \%$ of its GDP in R\&D, while Argentina invested $0.44 \%$, Chile invested $0.68 \%$, and Brazil invested $0.91 \%$ (Triunfol 2007). This poses an important risk for the successful development of a nascent field, such as genomic medicine, in Mexico. Indeed, the Mexican Government has made an important commitment to successfully set the basis for this promising venture, but it is essential to improve the context for public R\&D in Mexico and maintain up-to-date technological infrastructure. To ease this challenge, there are several initiatives to secure additional support for genomic medicine, including competing for international grant opportunities and increasing the participation of the private sector in research and development. Currently, $\sim 35 \%$ of expenditures in science and technology in Mexico are funded by the industrial sector (OECD 2008). Although this percentage is on the lower end of the OECD country members, strategic alliances are being established between industry and public research institutions for specific projects, including those in genomic medicine.

Other regulation challenges play an important role in successfully developing genomic medicine. Some of them are related to importing equipment and chemicals from other countries. This is particularly important for genomic technologies of recent generation, since its purchase results in a significant cost in duties and customs fees, which are typically covered by research budgets. In addition, over-regulation and long customs procedures damage a number of pieces of equipment and delay the timely progress of research projects.

As genomic medicine develops in Mexico, the need for modern legislation related to its ethical and social implications will also increase. Issues such as discrimination, confidentiality, equal access to medical benefits, and financial and workplace implications, among others, will require regulations based on Mexican laws. INMEGEN is the official reference center in genomic medicine, and it has a significant interaction with the Mexican Congress for matters related to this field.

There have been valuable lessons learned during the planning and implementation of this strategy. Some of these may be useful to similar emerging economies interested in developing genomic medicine. These include careful planning with equal participation of the main health, educational, scientific, and philanthropic organizations, which requires a robust senior leadership to coordinate the efforts. It is important to survey the availability of academic, scientific, financial, and political capacities to set feasible goals. It is useful to take advantage of previous local successful and unsuccessful experiences to design a more effective effort, focus on ambitious but realistic goals, and define specific milestones. These must include training programs, development of infrastructure, and selected alliances. In addition, it is desirable to include the translational component of scientific

\section{Genome Research}

www.genome.org 
research to make programs more appealing to private-public investment and contribute to knowledge economy.

Despite the many challenges ahead, Mexico's efforts in genomic medicine have successfully developed during these initial years. There is still a long way to go, but the careful planning and serious commitments of the different members of Mexican society coupled with solid alliances in progress anticipate Mexico's successful development of genomic medicine to benefit the healthcare of its population. In addition, its scientific work, infrastructure, and commitment to innovation will influence Latin America and will allow Mexico to engage in the global transition to a knowledge-based economy.

\section{References}

Aguilar-Diaz, H., Bobes, R.J., Carrero, J.C., Camacho-Carranza, R., Cervantes, C., Cevallos, M.A., Davila, G., Rodriguez-Dorantes, M., Escobedo, G., Fernandez, J.L., et al. 2006. The genome project of Taenia solium. Parasitol. Int. 55: S127-S130.

Arellano, J., Vallejo, M., Jimenez, J., Mintz, G., and Kretschmer, R.R. 1984. HLA-B27 and ankylosing spondylitis in the Mexican Mestizo population. Tissue Antigens 23: 112-116.

Baca, V., Velazquez-Cruz, R., Salas-Martinez, G., Espinosa-Rosales, F., Saldana-Alvarez, Y., and Orozco, L. 2006. Association analysis of the PTPN22 gene in childhood-onset systemic lupus erythematosus in Mexican population. Genes Immun. 7: 693-695.

Bekker-Mendez, C., Yamamoto-Furusho, J.K., Vargas-Alarcon, G., Ize-Ludlow, D., Alcocer-Varela, J., and Granados, J. 1998. Haplotype distribution of class II MHC genes in Mexican patients with systemic lupus erythematosus. Scand. J. Rheumatol. 27: 373-376.

Blattner, F.R., Plunkett 3rd, G., Bloch, C.A., Perna, N.T., Burland, V., Riley, M., Collado-Vides, J., Glasner, J.D., Rode, C.K., Mayhew, G.F., et al. 1997. The complete genome sequence of Escherichia coli K-12. Science 277: 1453-1474.

Davalos, I.P., Olivares, N., Castillo, M.T., Cantu, J.M., Ibarra, B., Sandoval, L., Moran, M.C., Gallegos, M.P., Chakraborty, R., and Rivas, F. 2000. The C677T polymorphism of the methylenetetrahydrofolate reductase gene in Mexican mestizo neural-tube defect parents, control mestizo and native populations. Ann. Genet. 43: 89-92.

Easton, D.F., Pooley, K.A., Dunning, A.M., Pharoah, P.D., Thompson, D., Ballinger, D.G., Struewing, J.P., Morrison, J., Field, H., Luben, R., et al. 2007. Genome-wide association study identifies novel breast cancer susceptibility loci. Nature. 447: 1087-1093.

Foro Consultivo Científico y Tecnológico. 2006. Diagnóstico de la polífica científica, tecnológica y de fomento a la innovación en México (2000-2006). Foro Consultivo Científico y Tecnológico, Mexico City, Mexico.

Fraga, A., Gorodezky, C., Lavalle, C., Castro-Escobar, L.E., Magana, L., and Escobar-Gutierrez, A. 1979. HIA-B27 in Mexican patients with ankylosing spondylitis. Arthritis Rheum. 22: 302. doi: 10.1002/art.1780220315.

Gerhard, P. 1986. Geografia historica de la Nueva España, 1519-1821. Universidad Nacional Autónoma de México (UNAM). Mexico City.

Gerhard, P. 1991. La frontera sureste de la Nueva España. Universidad Nacional Autonoma de Mexico (UNAM). Mexico City.

Gerhard, P. 1996. La frontera norte de la Nueva España. Universidad Nacional Autónoma de México (UNAM). Mexico City.

Gonzalez Burchard, E., Borrell, L.N., Choudhry, S., Naqvi, M., Tsai, H.J., Rodriguez-Santana, J.R., Chapela, R., Rogers, S.D., Mei, R., Rodriguez-Cintron, W., et al. 2005. Latino populations: A unique opportunity for the study of race, genetics, and social environment in epidemiological research. Am. J. Public Health 95: 2161-2168.

Gonzalez, V., Santamaria, R.I., Bustos, P., Hernandez-Gonzalez, I., Medrano-Soto, A., Moreno-Hagelsieb, G., Janga, S.C., Ramirez, M.A., Jimenez-Jacinto, V., Collado-Vides, J., et al. 2006. The partitioned Rhizobium etli genome: Genetic and metabolic redundancy in seven interacting replicons. Proc. Natl. Acad. Sci. 103: 3834-3839.

Gorodezky, C., Olivares, A., Debazo, H., Rodriguez, L., Altamirano, N., and Robles, C. 1995. [MHC-dependent molecular mechanisms of susceptibility and protection in type I diabetes in Mexicans]. Gac. Med. Mex. 131: 395-403.

Gueant-Rodriguez, R.M., Gueant, J.L., Debard, R., Thirion, S., Hong L.X., Bronowicki, J.P., Namour, F., Chabi, N.W., Sanni, A., Anello, G., et al. 2006. Prevalence of methylenetetrahydrofolate reductase
677T and 1298C alleles and folate status: A comparative study in Mexican, West African, and European populations. Am. J. Clin. Nutr. 83: 701-707.

Hidalgo, A., Baudis, M., Petersen, I., Arreola, H., Pina, P., Vazquez-Ortiz, G., Hernandez, D., Gonzalez, J., Lazos, M., Lopez, R., et al. 2005. Microarray comparative genomic hybridization detection of chromosomal imbalances in uterine cervix carcinoma. BMC Cancer 5: 77 . doi: 10.1186/1471-2407-5-77.

Iafrate, A.J., Feuk, L., Rivera, M.N., Listewnik, M.L., Donahoe, P.K., Qi, Y., Scherer, S.W., and Lee, C. 2004. Detection of large-scale variation in the human genome. Nat. Genet. 36: 949-951.

Instituto Nacional de Estadística Geografía e Informática (INEGI). 2005. II Conteo de población y vivienda 2005. Mexico.

The International HapMap Consortium. 2005. A haplotype map of the human genome. Nature 437: 1299-1320.

International Human Genome Sequencing Consortium. 2004. Finishing the euchromatic sequence of the human genome. Nature 431: 931-945.

Jimenez-Sanchez, G. 2003. Developing a platform for genomic medicine in Mexico. Science 300: 295-296.

Jimenez-Sanchez, G. 2004. Programa de Trabajo para dirigir el Instituto Nacional de Medicina Genómica 2004-2009. Fundación Mexicana para la Salud., Mexico D.F.

Jimenez-Sanchez, G., Childs, B., and Valle, D. 2001. Human disease genes. Nature 409: 853-855.

Jimenez-Sanchez, G., Valdes Olmedo, J., and Soberon, G. 2002a. Desarrollo de la medicina genómica en México. Este Pais 139: 17-23.

Jimenez-Sanchez, G., Valdes Olmedo, J., and Soberon, G. 2002b. El Instituto Nacional de Medicina Genómica [The National Institute of Genomic Medicine]. Este Pais 141: 50-56.

Kaiser, J. 2008. DNA sequencing. A plan to capture human diversity in 1000 genomes. Science 319: 395. doi: 10.1126/science.319.5862.395.

Lacasana-Navarro, M., Galvan-Portillo, M., Chen, J., Lopez-Cervantes, M., and Lopez-Carrillo, L. 2006. Methylenetetrahydrofolate reductase $677 \mathrm{C}>\mathrm{T}$ polymorphism and gastric cancer susceptibility in Mexico. Eur. J. Cancer 42: 528-533.

Lopez, M., Guerrero, J., Jung-Cook, H., and Alonso, M.E. 2005. CYP2D6 genotype and phenotype determination in a Mexican Mestizo population. Eur. J. Clin. Pharmacol. 61: 749-754.

Mathew, C.G. 2008. New links to the pathogenesis of Crohn disease provided by genome-wide association scans. Nat. Rev. Genet. 9: 9-14.

Munoz, J.B., Lacasana, M., Cavazos, R.G., Borja-Aburto, V.H., Galaviz-Hernandez, C., and Garduno, C.A. 2007. Methylenetetrahydrofolate reductase gene polymorphisms and the risk of anencephaly in Mexico. Mol. Hum. Reprod. 13: 419-424.

Olaiz-Fernández, G., Rivera-Dommarco, J., Shamah-Levy, T., Rojas, R., Villalpando-Hernández, S., Hernández-Avila, M., and Sepúlveda-Amor, J. 2006. Encuesta Nacional de Salud y Nutricion 2006 Instituto Nacional de Salud Publica 2006, Cuernavaca, Mexico.

Organisation for Economic Co-operation and Development (OECD). 2008. Main science and technology indicators 2008-1. OECD, Paris, France. http://www.oecd.org/document/26/0,2340,en_2825_497105_ 1901082 1_1_1_1,00.html.

Palacios, R. and Collado-Vides, J. 2007. Development of genomic sciences in Mexico: A good start and a long way to go. PLoS Comput. Biol. 3: 1670-1673.

Parra-Rojas, I., Ruiz-Madrigal, B., Martinez-Lopez, E., and Panduro, A. 2006. Influence of the -308 TNF-alpha and -174 IL-6 polymorphisms on lipid profile in Mexican subjects. Hereditas 143: 167-172.

Perez-Luque, E., Alaez, C., Malacara, J.M., Garay, M.E., Fajardo, M.E., Nava, L.E., and Gorodezky, C. 2003. Protective effect of DRB1 locus against type 2 diabetes mellitus in Mexican Mestizos. Hum. Immunol. 64: $110-118$.

Perez-Plasencia, C., Riggins, G., Vazquez-Ortiz, G., Moreno, J., Arreola, H., Hidalgo, A., Pina-Sanchez, P., and Salcedo, M. 2005. Characterization of the global profile of genes expressed in cervical epithelium by Serial Analysis of Gene Expression (SAGE). BMC Genomics 6: 130. doi: 10.1186/1471-21645-6-130.

Prokunina, L., Castillejo-Lopez, C., Oberg, F., Gunnarsson, I., Berg, L., Magnusson, V., Brookes, A.J., Tentler, D., Kristjansdottir, H., Grondal, G., et al. 2002. A regulatory polymorphism in PDCD1 is associated with susceptibility to systemic lupus erythematosus in humans. Nat. Genet. 32: 666-669.

Salamanca, F. and Armendares, S. 1995. The development of human genetics in Mexico. Arch. Med. Res. (Suppl) 26: S55-S62.

Sanchez-Corona, J., Flores-Martinez, S.E., Machorro-Lazo, M.V., Galaviz-Hernandez, C., Moran-Moguel, M.C., Perea, F.J., Mujica-Lopez, K.I., Vargas-Ancona, L., Laviada-Molina, H.A., Fernandez, V., et al. 2004. Polymorphisms in candidate genes for type 2 diabetes mellitus in a Mexican population with metabolic syndrome findings. Diabetes Res. Clin. Pract. 63: 47-55. 
Jimenez-Sanchez et al.

Sebat, J., Lakshmi, B., Troge, J., Alexander, J., Young, J., Lundin, P., Maner, S., Massa, H., Walker, M., Chi, M., et al. 2004. Large-scale copy number polymorphism in the human genome. Science 305: 525-528.

Seguim, B., Essajee, S., Jimenez-Sanchez, G., Singer, P., and Daar, A. 2007. Human genomic variation studies and pharmacogenomics are critical for global health. In Pharmacogenomics in admixed populations. (ed. G. Suarez-Kurtz.). Bandes Bioscience, Rio de Janeiro, Brazil.

Sosa-Macias, M., Elizondo, G., Flores-Perez, C., Flores-Perez, J., Bradley-Alvarez, F., Alanis-Banuelos, R.E., and Lares-Asseff, I. 2006. CYP2D6 genotype and phenotype in Amerindians of Tepehuano origin and Mestizos of Durango, Mexico. J. Clin. Pharmacol. 46: $527-536$.

Torres-Sanchez, L., Chen, J., Diaz-Sanchez, Y., Palomeque, C., Bottiglieri, T., Lopez-Cervantes, M., and Lopez-Carrillo, L. 2006. Dietary and genetic determinants of homocysteine levels among Mexican women of reproductive age. Eur. J. Clin. Nutr. 60: 691-697.

Triunfol, M.L. 2007. Latin American science moves into the spotlight. Cell 131: 1213-1216.

Valladares, A., Hernandez, N.G., Gomez, F.S., Curiel-Quezada, E., Madrigal-Bujaidar, E., Vergara, M.D., Martinez, M.S., and Arenas Aranda, D.J. 2006. Genetic expression profiles and chromosomal alterations in sporadic breast cancer in Mexican women. Cancer Genet. Cytogenet. 170: 147-151.

Vargas-Alarcon, G., Granados, J., Ibanez de Kasep, G., Alcocer-Varela, J., and Alarcon-Segovia, D. 1995. Association of HLA-DR5 (DR11) with systemic sclerosis (scleroderma) in Mexican patients. Clin. Exp. Rheumatol. 13: 11-16.

Vazquez-Ortiz, G., Garcia, J.A., Ciudad, C.J., Noe, V., Penuelas, S., Lopez-Romero, R., Mendoza-Lorenzo, P., Pina-Sanchez, P., and Salcedo, M. 2007. Differentially expressed genes between high-risk human papillomavirus types in human cervical cancer cells. Int. J. Gynecol. Cancer 17: 484-491.
Velazquez-Cruz, R., Orozco, L., Espinosa-Rosales, F., Carreno-Manjarrez, R., Solis-Vallejo, E., Lopez-Lara, N.D., Ruiz-Lopez, I.K., Rodriguez-Lozano, A.L., Estrada-Gil, J.K., Jimenez-Sanchez, G., et al. 2007. Association of PDCD1 polymorphisms with childhood-onset systemic lupus erythematosus. Eur. J. Hum. Genet. 15: 336-341.

Villarreal-Molina, M.T., Aguilar-Salinas, C.A., Rodriguez-Cruz, M., Riano, D., Villalobos-Comparan, M., Coral-Vazquez, R., Menjivar, M. Yescas-Gomez, P., Konisberg-Fainstein, M., Romero-Hidalgo, S., et al. 2007. The ABCA1 R230C variant affects HDL-cholesterol levels and body mass index in the Mexican population: Association with obesity and obesity-related comorbidities. Diabetes 56: 1881-1887.

Wakeley, J., Nielsen, R., Liu-Cordero, S.N., and Ardlie, K. 2001. The discovery of single-nucleotide polymorphisms-and inferences about human demographic history. Am. J. Hum. Genet. 69: 1332-1347.

Weissglas-Volkov, D., Huertas-Vazquez, A., Suviolahti, E., Lee, J., Plaisier, C., Canizales-Quinteros, S., Tusie-Luna, T., Aguilar-Salinas, C., Taskinen, M.R., and Pajukanta, P. 2006. Common hepatic nuclear factor-4alpha variants are associated with high serum lipid levels and the metabolic syndrome. Diabetes 55: 1970-1977.

The Wellcome Trust Case Control Consortium. 2007. Genome-wide association study of 14,000 cases of seven common diseases and 3,000 shared controls. Nature 447: 661-678.

Wilcken, B., Bamforth, F., Li, Z., Zhu, H., Ritvanen, A., Renlund, M. Stoll, C., Alembik, Y., Dott, B., Czeizel, A.E., et al. 2003. Geographical and ethnic variation of the $677 \mathrm{C}>\mathrm{T}$ allele of 5,10 methylenetetrahydrofolate reductase (MTHFR): Findings from over 7000 newborns from 16 areas world wide. J. Med. Genet. 40: $619-625$.

Zanke, B.W., Greenwood, C.M., Rangrej, J., Kustra, R., Tenesa, A., Farrington, S.M., Prendergast, J., Olschwang, S., Chiang, T., Crowdy, E., et al. 2007. Genome-wide association scan identifies a colorectal cancer susceptibility locus on chromosome 8q24. Nat. Genet. 39: 989-994. 


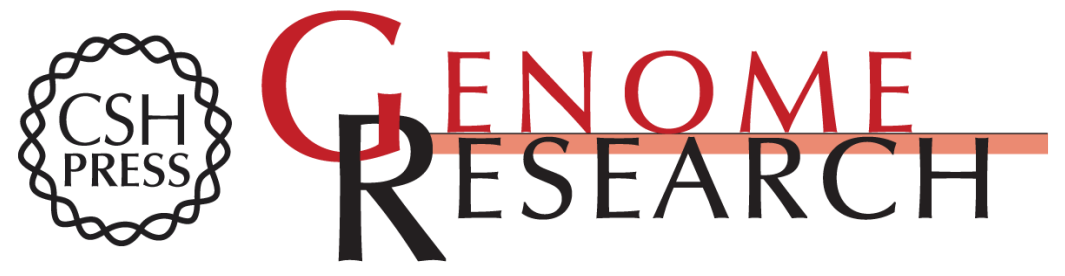

\section{Genomic medicine in Mexico: Initial steps and the road ahead}

Gerardo Jimenez-Sanchez, Irma Silva-Zolezzi, Alfredo Hidalgo, et al.

Genome Res. 2008 18: 1191-1198

Access the most recent version at doi:10.1101/gr.065359.107

References This article cites 46 articles, 9 of which can be accessed free at: http://genome.cshlp.org/content/18/8/1191.full.html\#ref-list-1

Open Access Freely available online through the Genome Research Open Access option.

License Freely available online through the Genome Research Open Access option.

Email Alerting Receive free email alerts when new articles cite this article - sign up in the box at the Service top right corner of the article or click here.

\section{Affordable, Accurate Sequencing.}

To subscribe to Genome Research go to: https://genome.cshlp.org/subscriptions 